\title{
INFLUÊNCIA DA COBERTURA MORTA VEGETAL E DA SALINIDADE SOBRE AS TROCAS GASOSAS DE GENÓTIPOS DE AMENDOIM
}

\author{
INFLUENCE OF DEAD VEGETABLE COVERAGE AND SALINITY ON THE GAS \\ EXCHANGES OF PEANUT GENOTYPES
}

\section{Carla Ingryd Nojosa Lessa ${ }^{1 *}$, Geocleber Gomes de Sousa ${ }^{2} \oplus$, Henderson Castelo Sousa ${ }^{3} \oplus$, Francisco Barroso da Silva Junior ${ }^{\oplus}$, José Thomas Machado de Sousa $^{\circledR} \oplus$, Claudivan Feitosa de Lacerda $^{5}$}

\footnotetext{
${ }^{1}$ Mestranda em Engenharia Agrícola, Universidade Federal do Ceará, Departamento de Engenharia Agrícola, Fortaleza, CE, Brasil.

${ }^{2}$ Professor, Universidade da Integração Internacional da Lusofonia Afro-Brasileira, Redenção, CE, Brasil.

${ }^{3}$ Mestrando em Engenharia Agrícola, Universidade Federal do Ceará, Departamento de Engenharia Agrícola, Fortaleza, CE, Brasil.

${ }^{4}$ Mestrando em Ciência do Solo, Universidade Federal do Ceará, Departamento de Ciências do Solo, Fortaleza, CE, Brasil.

${ }^{5}$ Professor, Universidade Federal do Ceará, Departamento de Engenharia Agrícola, Fortaleza, CE, Brasil.
}

RESUMO: Objetivou-se avaliar os parâmetros fisiológicos em diferentes acessos de amendoim sob estresse salino na presença e ausência de cobertura morta. O experimento foi conduzido na Universidade da Integração Internacional da Lusofonia Afro-Brasileira (UNILAB), campus Auroras, Redenção, Ceará. O delineamento experimental foi inteiramente casualizado (DIC), em arranjo fatorial $2 \times 2 \times 2$, referente aos valores de condutividade elétrica da água de irrigação $\left(1,0\right.$ e 5,0 dS m $\left.\mathrm{m}^{-1}\right)$, dois genótipos de amendoim (cultivar BR-1 e Acesso 43) e cobertura (com e sem cobertura) com quatro repetições. Foram analisadas as seguintes variáveis: temperatura foliar, concentração interna de carbono, transpiração, condutância estomática, fotossíntese, clorofila e eficiência do uso da água. A água de $5,0 \mathrm{dS} \mathrm{m}^{-1}$ proporcionou redução da fotossíntese, condutância estomática e eficiência do uso da água. O acesso BR-1 foi mais tolerante do que o acesso 43 ao estresse salino para a concentração interna de carbono. A cobertura morta elevou os valores de condutância estomática e eficiência do uso da água e reduziu na temperatura interna da folha. O BR-1 apresentou maiores valores de transpiração, condutância estomática, clorofila e menor valor de eficiência do uso da água comparado ao acesso 43.

Palavras-chave: Arachis hypogaea L., salinidade, proteção do solo

\begin{abstract}
The objective was to evaluate the physiological parameters in diferente accessions of peanuts under salt stress in the presence and absence of mulch. The experimente was conducted at the University of International Integration of Afro-Brazilian Lusophony (UNILAB), Auroras campus, Redenção, Ceará. The experimental design was completely randomized (DIC), in a $2 \times 2 \times 2$ factorial arrangement, referring to the electrical conductivity values of the irrigation water $\left(1.0\right.$ and $\left.5.0 \mathrm{dS} \mathrm{m}^{-1}\right)$, two peanut genotypes (cultivar BR-1 and Access 43) and coverage (with and without coverage) with four repetitions. The following variables were analyzed: leaf temperature, internal carbono concentration, transpiration, stomatal conductance, photosynthesis, chlorophyll, water use efficiency. The $5.0 \mathrm{dS} \mathrm{m} \mathrm{m}^{-1}$ water provided a reduction in photosynthesis, stomatal conductance and water use efficiency. BR-1 access was more tolerant than access 43 to salt stress for internal carbon concentration. The mulch increased the values of stomatal conductance and water use efficiency and reduced the internal temperature of the leaf. BR-1 showed higher values of transpiration, stomatal conductance, chlorophyll and lower water use efficiency compared to access 43 .
\end{abstract}

Key words: Arachis hypogaea L., salinity, soil protection 


\section{INTRODUÇÃ̃O}

O amendoim (Arachis hypogaea L.) apresenta grande importância econômica e é uma oleaginosa cultivada em vários locais, servindo como insumo de indústrias químicas e alimentícia, apresentando grande importância econômica em muitos países integrando cadeias de produção que envolve confeitos e óleo vegetal (MARTINS, VICENTE; 2010).

A agricultura praticada no semiárido brasileiro tem enfrentado cada vez mais problemas com a falta de água, ou seja, a irrigação e a escassez de água de boa qualidade tem aumentado a pressão sobre os empreendimentos agrícolas (LACERDA et al., 2016). Esse problema causa a inibição do crescimento de plantas submetidas à salinidade provocando dois distintos componentes do estresse salino: o primeiro se deve ao efeito osmótico, que reduz a absorção de água; e o segundo ocorre pelo efeito iônico provocado pelo excesso dos íons $\mathrm{Na}^{+}$e $\mathrm{Cl}^{-}$e da alterada relação $\mathrm{K}^{+} / \mathrm{Na}^{+}$e outros nutrientes (WILLADINO, CAMARA; 2010).

Os sais em excessos tendem a modificar as funções fisiológicas e bioquímicas das plantas, fazendo com que ocorra o fechamento dos estômatos e redução da transpiração e a fotossíntese (TAIZ et al., 2017). Estudando as respostas fisiológicas do feijão-fava submetidos ao estresse salino, Pereira Filho et al. (2019) constataram que houve redução das variáveis com o aumento da concentração de sais.

A utilização da cobertura vegetal sob o solo, surge como uma estratégia de prática de manejo conservacionistas para atenuar o estresse salino. Lessa et al. (2019) trabalhando com a cultura do sorgo sob estresse salino e uso de cobertura morta, verificaram que a proteção do solo minimizou os efeitos deletérios dos sais.

Com isso, objetivou-se avaliar parâmetros fisiológicos em diferentes acessos de amendoim sob estresse salino na presença e ausência de cobertura morta.

\section{MATERIAL E MÉTODOS}

O experimento foi conduzido de janeiro a março de 2019, na área experimental da Unidade de Produção de Mudas Auroras (UPMA), pertencente a Universidade da Integração Internacional da Lusofonia AfroBrasileira (UNILAB), Campus Auroras, Redenção, Ceará. Segundo a classificação de Köppen o clima da região é do tipo Aw', clima tropical com estação seca.

$\mathrm{O}$ delineamento experimental utilizado foi o inteiramente casualizado (DIC), em arranjo fatorial $2 \times 2 \times 2$, com 4 repetições, referente aos valores da condutividade elétrica da água de irrigação $\left(1,0\right.$ e 5,0 dS m $\left.\mathrm{m}^{-1}\right)$, dois genótipos de amendoim (cultivar BR-1 e Acesso 43) e cobertura (com e sem cobertura).

O acesso 43 é da espécie fastigiata, pertencente ao grupo Spanish e a cultivar BR1 é pertence ao grupo Valência. As sementes utilizadas foram concedidas pelo banco de acessos da UNILAB.

A semeadura foi realizada em substrato na proporção de 4:3:1, areia, arisco e esterco bovino, respectivamente, conduzida em vasos de plástico flexível com capacidade volumétrica de 8 litros. Aos 10 dias após a semeadura (DAS) foi realizado o desbaste manual, deixando-se duas plantas por vaso.

Para realizar a análise do substrato, o mesmo foi encaminhado para o laboratório da UFC, onde foram determinados os atributos químicos, indicados na Tabela 1 .

Tabela 1. Atributos químicos do substrato utilizado antes da aplicação da água salina

\begin{tabular}{|c|c|c|c|c|c|c|c|c|c|}
\hline M.O. & $\mathrm{N}$ & $\mathrm{P}$ & $\mathrm{Mg}$ & $\mathrm{K}$ & $\mathrm{Ca}$ & $\mathrm{Na}$ & \multirow[b]{2}{*}{$\mathrm{pH}$} & \multirow[b]{2}{*}{ PST (\%) } & \multirow{2}{*}{$\begin{array}{c}\text { CEes } \\
\left(\mathrm{dS} \mathrm{m}^{-1}\right) \\
\end{array}$} \\
\hline $\mathrm{g} \mathrm{kg}^{-1}$ & & $\mathrm{mg} \mathrm{kg}^{-1}$ & & & & & & & \\
\hline 4,34 & 0,26 & 65 & 1,2 & 0,65 & 1,2 & 0,33 & 6,2 & 7 & 1,19 \\
\hline
\end{tabular}

M.O = matéria orgânica; PST = porcentagem de sódio trocável; CEes = condutividade elétrica do extrato de saturação do solo

As águas utilizadas para irrigação foram preparadas utilizando-se os sais $\mathrm{NaCl}$,
$\mathrm{CaCl}_{2} \cdot \mathrm{H}_{2} \mathrm{O}, \mathrm{MgCl}_{2} \cdot 6 \mathrm{H}_{2} \mathrm{O}$, a quantidade dos mesmos foi determinada de modo a se obter a 
CEa desejada, na proporção 7:2:1, obedecendo sua relação entre $\mathrm{CEa}$ e sua concentração $\left(\right.$ mmol $\left._{\mathrm{c}} \mathrm{L}^{-1}=\mathrm{CE} \times 10\right)$ conforme Rhoades, Kandiah, Mashali (2000). A irrigação com água salina teve início após o desbaste (10 DAS).

O manejo da irrigação foi realizado obedecendo o princípio do lisímetro de drenagem proposto por Bernardo et al. (2019), mantendo o solo na capacidade de campo, com frequência diária, de forma manual e com fração de lixiviação de $15 \%$.

Aos 34 DAS, foram analisadas as seguintes variáveis: temperatura foliar (TI), concentração interna de carbono $(\mathrm{Ci})$, transpiração $(E)$, condutância estomática $(g s)$, fotosíntese $(A)$, utilizando-se o aparelho analisador de gás no infravermelho IRGA (LI 6400 XT da LICOR), em sistema aberto, com fluxo de ar de $300 \mathrm{~mL} \min ^{-1}$; as medições foram feitas entre 10 e $12 \mathrm{~h}$. De posse destes dados, foi quantificado a eficiência instantânea no uso da água (A/E). Em seguida, foram realizadas nas mesmas folhas as medições do índice relativo de clorofila (IRC), utilizandose método não destrutivo com um medidor portátil (SPAD - 502 Plus, Minolta, Japão).

Os dados das variáveis avaliadas foram submetidos à análise de variância (ANOVA), pelo teste de Tukey ao nível de 5\% (*) e $1 \%$ $(* *)$ de probabilidade, utilizando-se o programa computacional ASSISTAT. 7.7 Beta (SILVA; AZEVEDO, 2016).

\section{RESULTADOS E DISCUSSÃO}

De acordo com a análise de variância a interação dos fatores água e acesso exerceu efeito significativo apenas para as variáveis A e $\mathrm{Ci}(\mathrm{p} \leq 0,01)$. O fator água, de forma isolada, foi significativo para EUA, $g s$ e A $(\mathrm{p} \leq 0,01)$. Já $\mathrm{o}$ fator acesso, teve significância para clorofila e A $(\mathrm{p} \leq 0,05)$, EUA, $E$ e $g s(\mathrm{p} \leq 0,01)$. Para o fator cobertura, foi significativo para EUA ( $\mathrm{p} \leq 0,05), A, g s, C i, T I(\mathrm{p} \leq 0,01)$.

Tabela 1. Resumo da análise de variância (ANOVA) pelo quadrado médio para as variáveis de fotossíntese $(A)$, transpiração $(E)$, condutância estomática $(g s)$, concentração interna de carbono $(C i)$, eficiência do uso da água (EUA), clorofila, temperatura interna da folha $(T I)$, de acessos de amendoim em função da condutividade elétrica da água de irrigação, com e sem cobertura

\begin{tabular}{|c|c|c|c|c|c|c|c|c|}
\hline \multirow{2}{*}{$\mathrm{FV}$} & \multirow{2}{*}{ GL } & \multicolumn{7}{|c|}{ Quadrado médio } \\
\hline & & $A$ & $E$ & $g s$ & $C i$ & EUA & Clorofila & $T I$ \\
\hline Água (A) & 1 & $36,18 * *$ & $0,20^{\mathrm{ns}}$ & $0,28 * *$ & $353,78^{\mathrm{ns}}$ & $1,27 * *$ & $39,89 \mathrm{~ns}$ & $0,58^{\text {ns }}$ \\
\hline Acesso (Ac) & 1 & $2,94 *$ & $5,61 * *$ & $0,20 * *$ & $291,61^{\mathrm{ns}}$ & $1,02 * *$ & $103,71 *$ & $0,16^{\mathrm{ns}}$ \\
\hline Cobertura (C) & 1 & $9,29 * *$ & $0,82^{\text {ns }}$ & $0,11 * *$ & $808,22 * *$ & $0,54 *$ & $11,67^{\mathrm{ns}}$ & $3,36 * *$ \\
\hline $\mathrm{A} \times \mathrm{Ac}$ & 1 & $9,42 * *$ & $0,009^{\text {ns }}$ & $0,001^{\mathrm{ns}}$ & $760,5 * *$ & $0,25^{\mathrm{ns}}$ & $0,29^{\text {ns }}$ & $0,04^{\mathrm{ns}}$ \\
\hline $\mathrm{A} \times \mathrm{C}$ & 1 & $0,68^{\mathrm{ns}}$ & $0,11^{\mathrm{ns}}$ & $0,05^{\mathrm{ns}}$ & $134,72^{\mathrm{ns}}$ & $0,23^{\mathrm{ns}}$ & $56,84^{\mathrm{ns}}$ & $0,35^{\mathrm{ns}}$ \\
\hline Ac $x \mathrm{C}$ & 1 & $0,25^{\mathrm{ns}}$ & $0,26^{\mathrm{ns}}$ & $0,001^{\mathrm{ns}}$ & $6,24^{\mathrm{ns}}$ & $0,12^{\text {ns }}$ & $8,27^{\mathrm{ns}}$ & $0,07^{\mathrm{ns}}$ \\
\hline$A \times A c \times C$ & 1 & $2,77^{\mathrm{ns}}$ & $0,16^{\mathrm{ns}}$ & $0,02^{\mathrm{ns}}$ & $50,15^{\mathrm{ns}}$ & $0,02^{\mathrm{ns}}$ & $2,80^{\mathrm{ns}}$ & $0,39^{\text {ns }}$ \\
\hline Tratamento & 7 & $8,79 * *$ & $1,02^{\mathrm{ns}}$ & $0,09 * *$ & $343,6 * *$ & $0,49 * *$ & $31,92^{\mathrm{ns}}$ & $0,71^{\mathrm{ns}}$ \\
\hline Resíduo & 24 & 0,67 & 0,46 & 0,01 & 91,12 & 0,08 & 17,2 & 0,29 \\
\hline $\mathrm{CV}(\%)$ & & 4,93 & 13,24 & 19,08 & 3,35 & 8,8 & 12,88 & 1,53 \\
\hline
\end{tabular}

FV: Fonte de variação, GL: Grau de liberdade, CV (\%): Coeficiente de variação, **: Significativo ao nível de 1\% de probabilidade (p $\leq 0.01)$, *: Significativo ao nível de $5 \%$ de probabilidade $(\mathrm{p} \leq .05)$, ns: não significativo $(\mathrm{p}>0.05)$

Para a variável fotossíntese (Figura 1), os acessos estudados apresentaram reduções em seus valores quando irrigados com água de

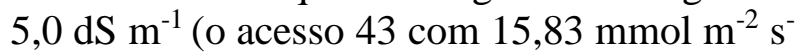
1 , e o BR-1 com 15,35 $\left.\mathrm{mmol} \mathrm{m}^{-2} \mathrm{~s}^{-1}\right)$. Quando irrigados com água de $1,0 \mathrm{dS} \mathrm{m} \mathrm{m}^{-1}$, o genótipo BR-1 obteve valores superiores comparado ao acesso $43\left(18,57\right.$ e $16,87 \mathrm{mmol} \mathrm{m} \mathrm{m}^{-2} \mathrm{~s}^{-1}$, respectivamente).
A redução da taxa fotossintética ocasionada devido ao aumento da salinidade da água de irrigação pode estar relacionada a diminuição da expansão celular que consequentemente inibe 0 processo fotossintético (NEVES et al., 2009), provocando um fechamento estomático parcial (GOMES et al., 2015). 


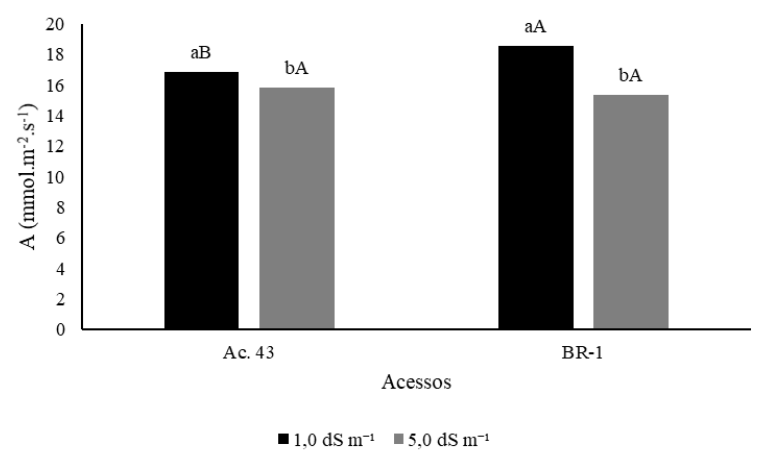

Figura 1. Fotossíntese sob estresse salino e diferentes acessos na cultura do amendoim

Queiroga et al. (2018) afirmam que a cultivar BR-1 é adaptada as condições de cultivo no Nordeste brasileiro, e Borges et al. (2007) relatam que os grupos correspondentes aos genótipos utilizados (Grupo Valência e Grupo Spanish) possuem variabilidade genética, podendo justificar a diferença dos valores de fotossíntese entre as mesmas.

Souza et al. (2019) trabalhando com a cultura da fava, observaram que o estresse salino afetou a fotossíntese, apresentando uma redução nos valores. E Jacinto Júnior et al. (2019), trabalhando com genótipos de fava, observaram que houve diferença nos valores de fotossíntese para os genótipos avaliados.

Observa-se na figura 2, que houve diferença significativa referente a transpiração, onde o genótipo BR-1 apresentou maiores valores. $\left(5,56 \mathrm{mmol} \mathrm{m}^{-2} \mathrm{~s}^{-1}\right)$

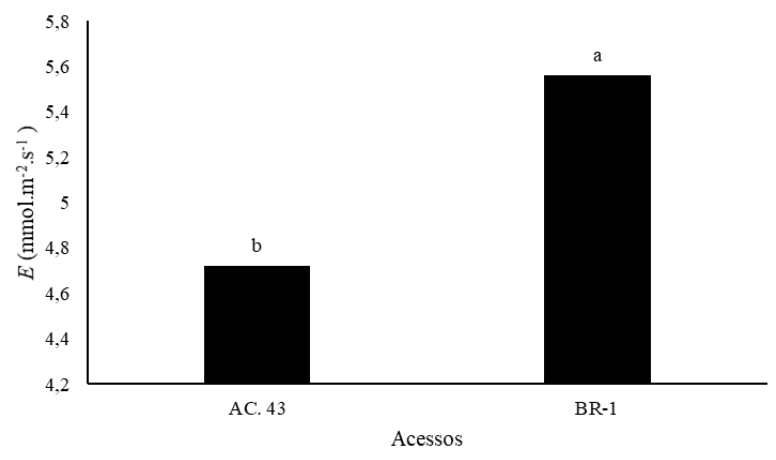

Figura 2. Transpiração $(E)$ em função dos acessos na cultura do amendoim

A redução de transpiração no acesso 43, segundo Azevedo Neto at al. (2009) se dá devido ser comum ocorrer reduções de transpiração em acessos, isso pode ser comprovado no presente trabalho, em que ocorreu diferença nos resultados dos acessos estudados. Resultados semelhantes foram encontrados pelos mesmos, onde obtiveram redução na taxa de transpiração em cinco genotipos de amendoim.

Como apresentado na figura $3 \mathrm{~A}$, o aumento da condutividade da água de irrigação ocasionou uma menor condutância estomática $\left(0,51 \mathrm{~mol} \mathrm{~m}^{-2} \mathrm{~s}^{-1}\right)$. Na figura $3 \mathrm{~B}$, os tratamentos com o acesso BR-1 $\left(0,69 \mathrm{~mol} \mathrm{~m}^{-2}\right.$ $\mathrm{s}^{-1}$ ), e na figura $3 \mathrm{C}$, os tratamentos com cobertura $\left(0,67 \mathrm{~mol} \mathrm{~m} \mathrm{~m}^{-2} \mathrm{~s}^{-1}\right)$ apresentaram maior valor de condutância estomática.
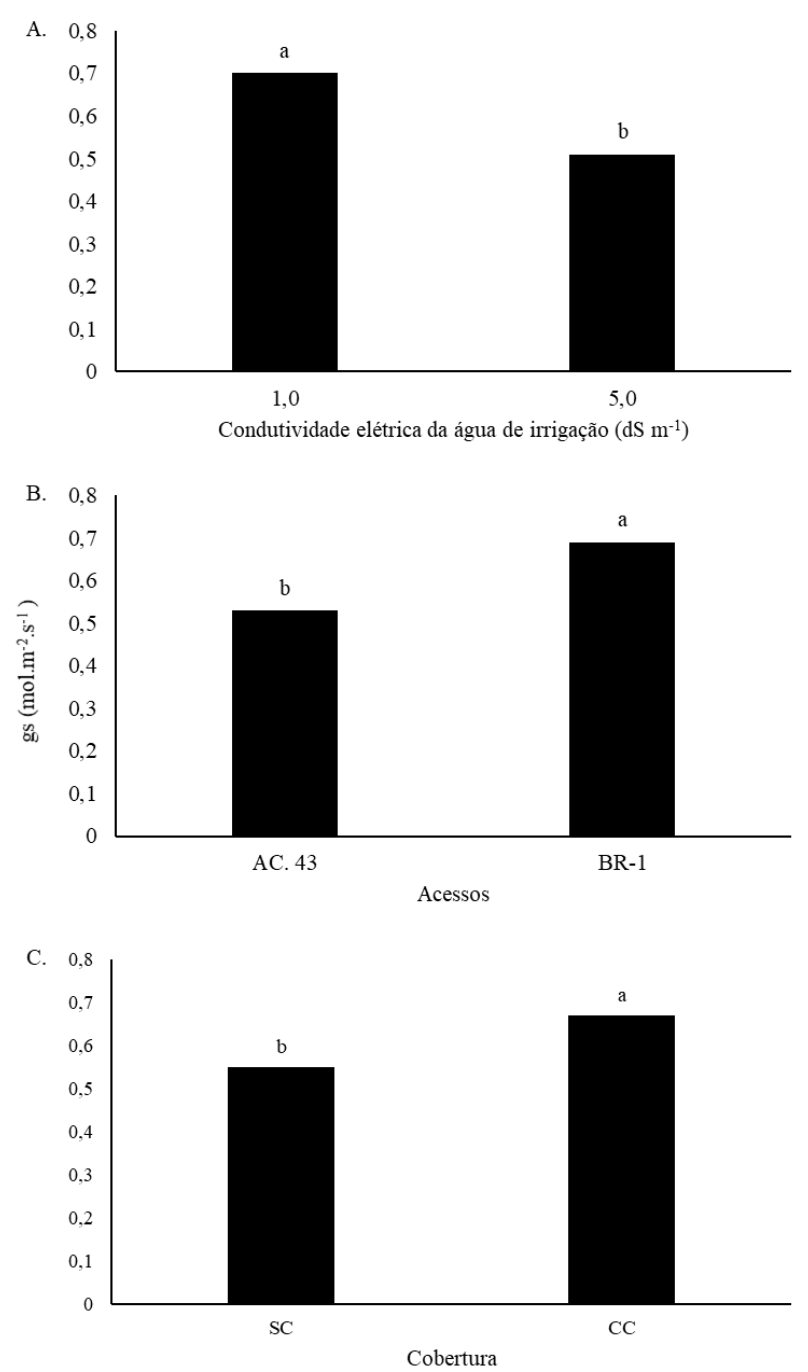

Figura 3. Condutância estomática $(g s)$ em função da condutividade elétrica da água de irrigação (A), acessos (B) e cobertura (C) na cultura do amendoim

Esta redução da condutância estomática ocorre devido à um mecanismo de fechamento dos estômatos, em que as plantas tentam reduzir a perda de água quando são 
submetidas ao estresse salino (LIMA et al., 2014). Resultados similares foram observados por Sousa et al. (2018) trabalhando com a cultura da fava, onde o aumento da salinidade resultou em uma redução da condutância estomática.

O valor da condutância estomática ser superior no genótipo BR-1, esta possivelmente relacionado as diferenças fisiológicas entre os acessos. Silva et al. (2016) estudando genótipos de feijão-caupi obtiveram diferenças entre os mesmos para condutância estomática.

$\mathrm{O}$ acréscimo no valor da condutância nos tratamentos com cobertura, é devido a maior retenção de água e consequentemente maior evapotranspiração. Resultados semelhantes foram encontrados por Freire et al. (2014), onde a condutância estomática foi elevada nos tratamentos com cobertura morta na cultura do maracujá.

Para a variável concentração interna de carbono (Figura 4), o acesso 43 obteve maiores resultados quando irrigado com água de 1,0 dS m $\mathrm{m}^{-1}$ (290,04 ppm). No entanto, o genótipo BR-1 apresentou maiores resultados quando irrigado com água de $5,0 \mathrm{dS} \mathrm{m} \mathrm{m}^{-1}$ $(289,43 \mathrm{ppm})$. Esse resultado provavelmente está relacionado à uma aclimatização do genótipo ao estresse salino, ou seja, obtendo maior ajustamento osmótico para as condições do estudo.

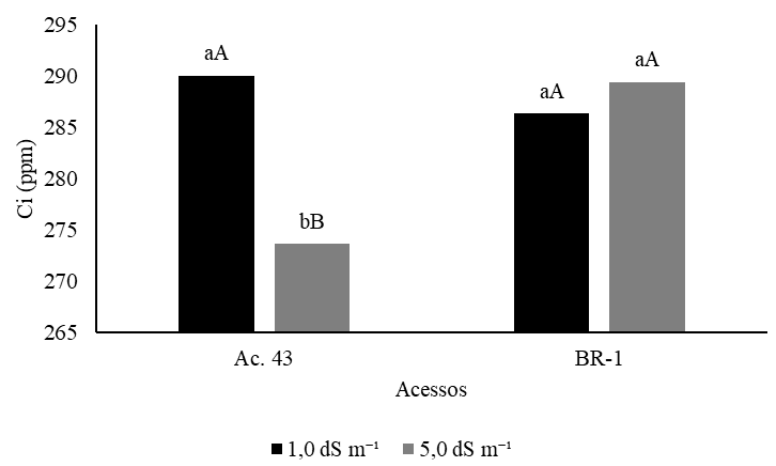

Figura 4. Concentração interna de carbono (Ci) sob estresse salino e diferentes acessos na cultura do amendoim

A salinidade promove distúrbios fisiológicos (FARIAS et al., 2009), este fato explica os resultados referente ao acesso 43 para a concentração interna de carbono. Os resultados do presente trabalho para concentração interna de carbono divergem dos resultados obtidos por Gomes et al. (2015) trabalhando com a cultura do girassol, onde observaram que o estresse salino não apresenta efeito sobre a concentração interna de carbono.

Observa-se que o tratamento com menor nível salino da água de irrigação propiciou maior valor da EUA com 3, $5 \mu \mathrm{mol}$ $\mathrm{CO}_{2}$ mol $\mathrm{H}_{2} \mathrm{O}^{-1}$ (Figura 5A). Os tratamentos com acesso 43, permitiram um maior valor da EUA com $3,48 \mu \mathrm{mol} \mathrm{CO} \mathrm{Col} \mathrm{H}_{2} \mathrm{O}^{-1}$ (Figura 5B). $\mathrm{E}$ os tratamentos com cobertura obtiveram uma menor EUA, com 3,43 $\mu \mathrm{mol}$ $\mathrm{CO}_{2} \mathrm{~mol} \mathrm{H}_{2} \mathrm{O}^{-1}$ (Figura 5C).
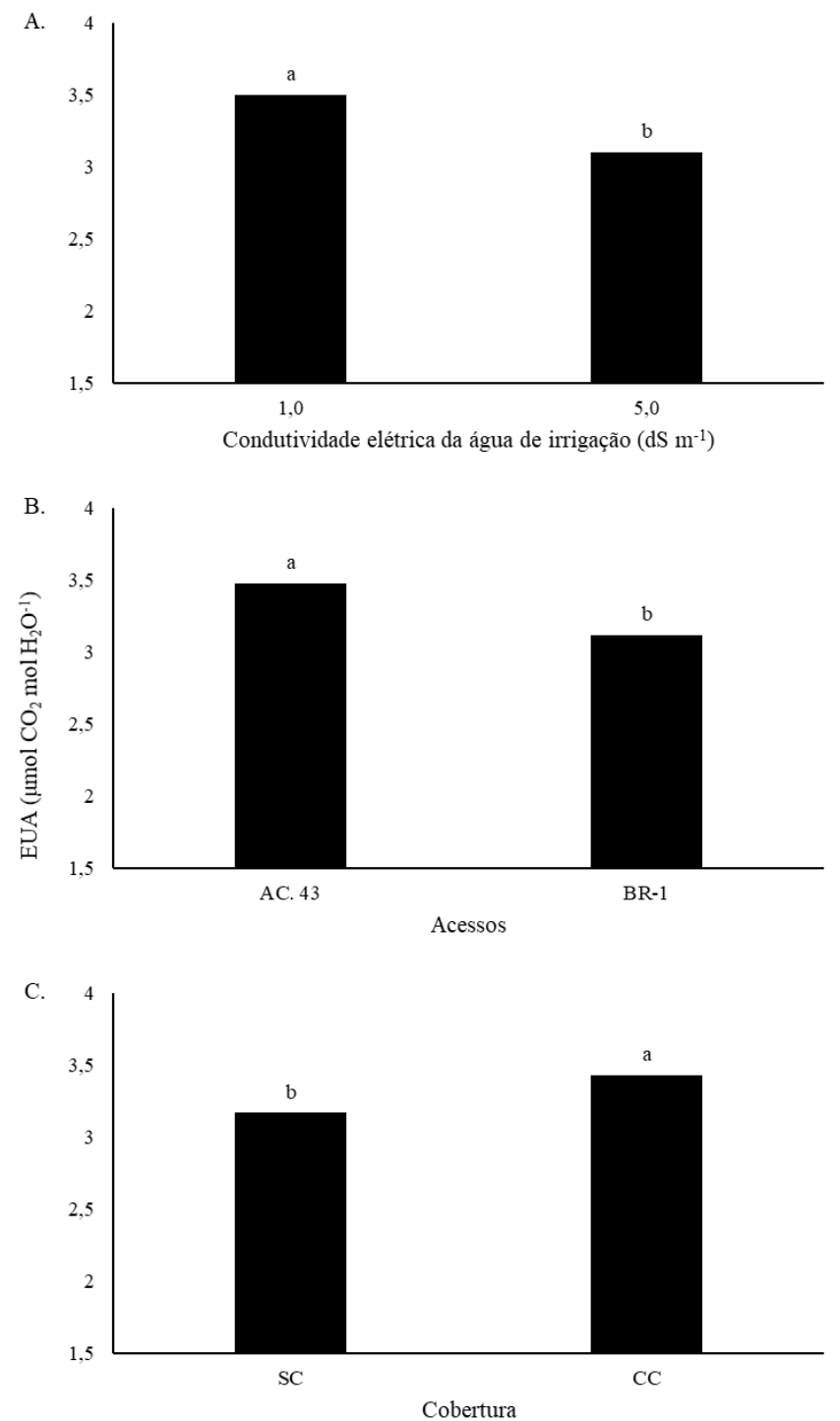

Figura 5. Eficiência do uso da água (EUA) em função da condutividade elétrica da água de irrigação (A), acessos (B) e cobertura (C) na cultura do amendoim 
O decréscimo da eficiência do uso da água (EUA) ocasionado pela salinidade, pode estar relacionado ao fato de que ocorre uma redução no consumo de água pelas plantas, consequentemente se tem uma baixa absorção de íons específicos, como forma de evitar efeitos tóxicos nas plantas (FLOWERS; FLOWERS, 2005). Resultados semelhantes foram encontrados por Nobre et al. (2014) em que o aumento da condutividade da água de irrigação ocasionou uma menor eficiência do uso da água pela mamoneira.

A baixa eficiência no uso da água para o genótipo BR-1 quando comparado ao acesso 43, pode estar relacionado a variabilidade existente entre os acessos da espécie (BORGES et al., 2007). Este resultado corrobora com os encontrados por Souza et al. (2016) trabalhando com a cultura do feijãocaupi, em que houve eficiência do uso da água pelo cultivar BRS Pujante.

$\mathrm{O}$ aumento da EUA devido à presença de cobertura morta demonstra a capacidade da mesma em manter uma maior umidade do solo, consequentemente reduzindo a temperatura do solo e reduzindo a perda de água, de forma a colaborar para o desenvolvimento da cultura (SOUZA et al., 2016). Resultados semelhantes foram encontrados por Carvalho et al. (2011), trabalhando com a cultura do repolho em que a cobertura do solo proporcionou uma maior eficiência do uso da água.

Conforme apresentado na figura 6, referente a clorofila, houve diferença significativa, onde o genótipo BR-1 apresentou maiores valores.

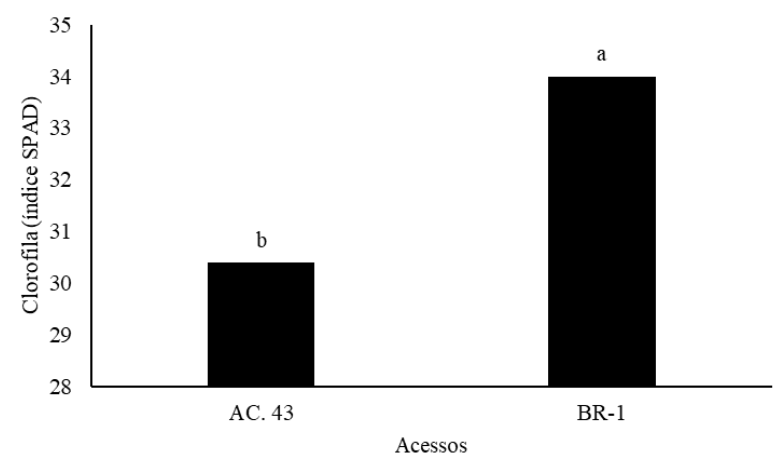

Figura 6. Clorofila em função dos acessos na cultura do amendoim
Em conformidade com Taiz et al. (2017), as espécies vegetais que apresentam maiores teores foliares de clorofila está relacionado a capacidade que as mesmas possuem em produzir fotoassimilados através da fotossíntese, contudo, a eficiência fotossintética está relacionada a outros fatores, tal como a taxa respiratória. Com isso, o BR-1 apresenta maior capacidade em produzir fotoassimilados. Resultados semelhantes foram encontrados por Gasparini (2015), que avaliando o efeito da radiação e temperatura em cinco acessos de pinhão manso, verificou que houve diferença significativa para clorofila entre os acessos.

De acordo com a figura 7, houve diferença significativa, onde os maiores valores da temperatura interna da folha foram obtidos nos tratamentos sem cobertura $(36,08$ $\left.{ }^{\circ} \mathrm{C}\right)$.

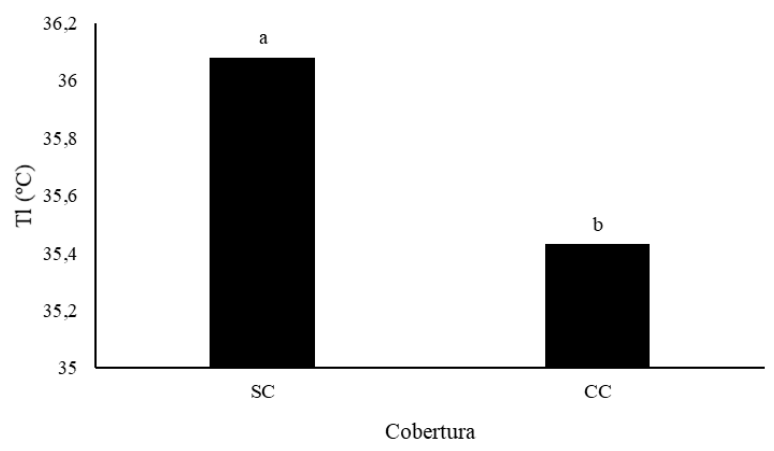

Figura 7. Temperatura interna da folha (TI) em função das coberturas na cultura do amendoim.

A redução de temperatura nos tratamentos com a presença de cobertura morta pode ser justificada devido a capacidade da mesma em manter o solo úmido e diminuir a sua temperatura (TEODORO et al., 2011). Com isso, as plantas nestas condições foram capazes de realizar o transporte de água para a parte aérea com maior eficiência conforme Taiz et al. (2017), mantendo a temperatura mais baixa.

\section{CONCLUSÕES}

A água de $5,0 \mathrm{dS} \mathrm{m}^{-1}$ proporcionou redução da fotossíntese, condutância estomática e eficiência do uso da água. 
$\mathrm{O}$ acesso BR-1 foi mais tolerante do que o acesso 43 ao estresse salino para a concentração interna de carbono.

A cobertura morta elevou os valores de condutância estomática e eficiência do uso da água e reduziu na temperatura interna da folha.

O BR-1 apresentou maiores valores de transpiração, condutância estomática, clorofila e menor valor de eficiência do uso da água comparado ao acesso 43.

\section{AGRADECIMENTOS}

À Fundação Cearense de Apoio ao Desenvolvimento Científico e Tecnológico (FUNCAP) pelo apoio financeiro.

\section{REFERÊNCIAS}

AZEVEDO NETO, A. D.; PRISCO, J. T. \& GOMES-FILHO, E. Changes in soluble amino-N, soluble proteins and free amino acids in leaves and roots of salt-stressed maize genotypes, Journal of Plant Interactions, v. 4, n. 2, p. 137-144, 2009.

BERNARDO, S.; MANTOVANI, E. C.; SILVA, D. D.; SOARES, A. A. Manual de irrigação. 9.ed. Viçosa: Editora UFV, 2019. $545 \mathrm{p}$.

BORGES, W. L., XAVIER, G. R., RUMJANEK, N. G. Variabilidade genética entre acessos de amendoim. Pesquisa Agropecuária Brasileira, v.42. n.8. p.11511157. 2007.

CARVAlHO, J. F.; MONTENEGRO, A. A. A.; SOARES, T. M.; SILVA, E. F. F.; MONTENEGRO, S. M. G. L. Produtividade do repolho utilizando cobertura morta e diferentes intervalos de irrigação com água moderadamente salina. Revista Brasileira de Engenharia Agrícola e Ambiental, v.15, n.3, p.256-263, 2011.
FARIAS, S. G. G.; SANTOS, D. R.; FREIRE, A. L. O.; SILVA, R. B. Estresse salino no crescimento inicial e nutrição mineral de Gliricídia (Gliricidia sepium (Jacq.) Kunt ex Steud) em solução nutritiva. Revista Brasileira de Ciência do Solo, v. 33, p. 14991505, 2009.

FLOWERS, T. J.; FLOWERS, S. A. Why does salinity pose such a difficult problem for plant breeders? Agricultural Water Management, v.78, p.15-24, 2005.

FREIRE, J. L. O.; DIAS, T. J.; CAVALCANTE, L. F.; FERNANDES, P. D.; LIMA NETO, A. J. Rendimento quântico e trocas gasosas em maracujazeiro amarelo sob salinidade hídrica, biofertilização e cobertura morta. Revista Ciência Agronômica, v. 45, n. 1, p. 82-91, 2014.

GASPARINI, X. S. S. Efeitos da radiação e da temperatura em cinco acessos de pinhão manso (Jatropha curcas L.): crescimento, fluorescência da clorofila a e floração. 2015. 68f. Dissertação. Universidade Federal do Espírito Santo, Vitória.

GOMES, K. R.; SOUSA, G. G.; LIMA, F. A.; VIANA, T. V. A.; AZEVEDO, B. M.; SILVA, G. L. Irrigação com água salina na cultura do girassol (Helianthus annuus L.) em solo com biofertilizante bovino. Revista Irriga, v.20, n.4, p.680-693, 2015.

JACINTO JÚNIOR, S. G.; MORAES, J. G. L.; SILVA, F. D. B.; SILVA, B. N.; SOUSA, G. G.; OLIVEIRA, L. L. B.; MESQUITA, R. O. Respostas fisiológicas de genótipos de fava (Phaseolus lunatus L.) submetidas ao estresse hídrico cultivadas no Estado do Ceará. Revista Brasileira de Meteorologia, v. 34, n. 3, p. 413- 422, 2019.

KÖPPEN, W. P. Die klimate der erde: Grundriss der klimakunde. Berlin: Walter de Gruyter \& So., 1923. 369p. 
LACERDA, C. F.; COSTA, R. N. T.; BEZERRA, M. A.; NEVES, A. L. R.; SOUSA, G. G.; GHEYI, H. R. Estratégias de manejo para uso de água salina na agricultura. In: GHEYI, H. R.; DIAS, N. S.; LACERDA, C. F.; GOMES FILHO, E. (Org). Manejo da salinidade na agricultura: estudos básicos aplicados. Fortaleza: INCTSal, 2016. p. 337352.

LESSA, C. I. N.; OLIVEIRA, A. C. N.; MAGALHÃES, C. L.; SOUSA, J. T. M.; SOUSA, G. G. Estresse salino, cobertura morta e turno de rega na cultura do sorgo. Revista Brasileira de Agricultura Irrigada. Edição Especial - IV SBRNS, Fortaleza, p. 3637 - 3645, 2019.

LIMA, G. S.; NOBRE, R. G.; GHEYI, H. R.; SOARES, L. A. A. Physiology, growth and yield of castor bean under salt stress and nitrogen doses in phenophases. IDESIA (Chile) V. 32, Nº 3, 2014.

MARTINS, R.; VICENTE, J. R. Demandas por inovação no amendoim paulista. Economia, v. 28, p. 2, 2010.

NEVES, A.L.R.; LACERDA, C.F.; GUIMARÃES, F.V.A.; GOMES-FILHO, E.; FEITOSA, D.R.C. Trocas gasosas e teores de minerais no feijão-decorda irrigado com água salina em diferentes estádios. Revista Brasileira de Engenharia Agrícola e Ambiental, v. 13, supl., p. 873- 881, 2009.

NOBRE, R. G.; LIMA, G. S.; GHEYI, H. R.; SOARES, L. A. A.; SILVA, A. O. Crescimento, consumo e eficiência do uso da água pela mamoneira sob estresse salino e nitrogênio. Revista Caatinga, v. 27, n. 2, p. $148-158,2014$.

PEREIRA FILHO, J. V.; VIANA, T. V. A.; SOUSA, G. G.; CHAGAS, K. L.; AZEVEDO, B. M.; PEREIRA, C. C. M. S. Physiological responses of lima bean subjected to salt and water stresses. Revista Brasileira de Engenharia Agrícola e Ambiental, v.23, n.12, p.959-965, 2019.
QUEIROGA, V. de P., ALMEIDA, F. de A. C., ALBUQUERQUE, E. M. B. Produção da matéria prima. In: Queiroga, V. de P., Almeida, F. de A. C., Girão, E. G., Neto, A. F., Albuquerque, E. M. B. Amendoim orgânico: tecnologia de produção para o nordeste brasileiro. Fortaleza: AREPB, 2018. Cap. 3, p.48-121.

RHOADES, J. D., KANDIAH, A., MASHALI, A. M. Uso de águas salinas para produção agrícola. Campina Grande: UFPB. 2000, 117p. Estudos da FAO, Irrigação e Drenagem.

SILVA, A.; BRITO, M. E. B.; FRADE, L. J. G.; NOBRE, R. G.; COSTA, F. B.; MELO, A. S.; SILVA, L. A. Crescimento e trocas gasosas de genótipos de feijão-caupi sob estratégias de cultivo. Revista Ambiente \& Água, vol. 11, n. 3, 2016.

SILVA, F. A. S.; AZEVEDO, C. A. V. The Assistat Software Version 7.7 and its use in the analysis of esperimental data. African Journal Agricultural, v. 11, p.3733-3740, 2016.

SOUSA, G. G.; SOUSA, C. H. C.; SOUZA, M. V. P.; FREIRE, M. H. C.; SILVA, G. L. TROCAS GASOSAS NA CULTURA DA FAVA IRRIGADA COM ÁGUAS SALINAS. Revista Irriga, Botucatu, v. 1, n. 2, p. 19-23, Edição Especial Winotec, 2018.

SOUZA, T. M. A.; SOUZA, T. A.; SOLTO, L. S.; SÁ, F. V. S.; PAIVA, E. P.; BRITO, M. E. B.; MESQUITA, E. F. Crescimento e trocas gasosas do feijão caupi cv. BRS Pujante sob níveis de água disponível no solo e cobertura morta. Revista Irriga, v. 21, n. 4, p. 796-805, 2016.

SOUZA, M. V. P.; SOUSA, G. G.; SALES, J. R. S.; FREIRE, M. H. C.; SILVA, G. L.; VIANA, T. V. A. Saline water and biofertilizer from bovine and goat manure in the Lima bean crop. Revista Brasileira de Ciências Agrárias, Recife, v.14, n.3, e5672, 2019. 
Influência da cobertura morta vegetal e da salinidade sobre as trocas gasosas de genótipos de amendoim

TAIZ, L.; ZEIGER, E.; MOLLER, I. M.; MURPHY, A. Fisiologia e desenvolvimento vegetal. 6. ed. Porto Alegre, RS: Artmed, 858 p. 2017.

TEODORO, R. B.; OLIVEIRA, F. L.; SILVA, D. M. N.; FÁVERO, C.; QUARESMA, M. A. L. Leguminosas herbáceas perenes para utilização como coberturas permanentes de solo na Caatinga Mineira. Revista Ciência Agronômica, v. 42, n. 2, p.292-300, 2011.

WILLADINO, L.; CAMARA, T. R. Tolerância das plantas à salinidade: aspectos fisiológicos e bioquímicos. Enciclopédia biosfera, v. 6, n. 11, p. 1-23, 2010. 